\title{
AGE DISTRIBUTION OF THE ONSET OF ESOTROPIA*
}

BY

\author{
W. NORDLÖW
}

Vänersborg, Sweden

INFORMATION concerning the age distribution of the onset of esotropia is important in several respects, especially in discussing the aetiology of strabis- $\stackrel{\circ}{\omega}$ mus. Previously, the age distribution was considered to support the refraction: theory and later the fusion theory, but more recently it has been considered if to support the reflex theory. The child's age at the onset of the strabismus ${ }_{0}^{\infty}$ must be taken into account in determining the factors which it is possible $\stackrel{\rho}{\rho}$ to examine directly, and the therapeutic measures which can be employed to counteract it.

\section{Review of the Literature}

During the past 50 years, the conception has been generally accepted that in the majority of cases, esotropia develops at the age of 2 to 4 years (Table I, opposite). This idea may be traced back to information published by several workers including Priestley Smith (1899) and Worth (1903).

Results deviating markedly from previous findings were published by Nordlöw (1942); these showed that the likelihood of developing esotropia is greatest 3 during the first year of life, and that thereafter the frequency of onset decreases gradually until the age of 6 years, when it ceases almost entirely. In the series of cases then reviewed, $44 \cdot 5$ per cent. were examined within 2 years of the development of the squint. Nordlöw (1942) also pointed out that information concerning age of onset, which was supplied a long time after the development of the squint, was less reliable. This preponderance of onset in the first year of life has since been 3 confirmed by Keiner $(1949,1951)$ and Scobee $(1951)$, who found that up to 55 per 9 cent. of all cases of esotropia develop during that period (Table I, overleaf). Keiner also stated that it had been present since birth in 18.4 per cent. of cases, and Scobee in 27.4 per cent. Nordlöw's figures indicate that the age distribution of the onset of intermittent esotropia differs from that found in a mixed group of cases of permanent and intermittent strabismus.

\section{Method and Sources of Error}

This investigation is based upon information given by the children's parents within 7 years of the stated time of onset. It is important to be aware of possible sources of error $\frac{\vec{\Phi}}{\mathbb{*}}$ in this method of investigation, for if these are observed and allowed for it should be possible

* Received for publication July 31, 1953. 
TABLE I

AGE DISTRIBUTION OF ONSET OF ESOTROPIA

\begin{tabular}{|c|c|c|c|c|c|c|c|c|c|c|c|c|c|c|}
\hline \multirow{3}{*}{ Author } & \multirow{3}{*}{ Year } & \multirow{3}{*}{$\begin{array}{l}\text { Case } \\
\text { Histories } \\
\text { Given }\end{array}$} & \multirow{3}{*}{$\begin{array}{c}\text { Age at First } \\
\text { Examination } \\
(y r s)\end{array}$} & \multirow{3}{*}{$\begin{array}{c}\text { Type of } \\
\text { Squint }\end{array}$} & \multirow{3}{*}{ No. } & \multicolumn{7}{|c|}{ Age at Onset of Squint (yrs) } & \multirow{3}{*}{$6-7$} & \multirow{3}{*}{$7-8$} \\
\hline & & & & & & Up & to 1 & \multirow{2}{*}{$1-2$} & \multirow{2}{*}{$2-3$} & \multirow{2}{*}{$3-4$} & \multirow{2}{*}{$4-5$} & \multirow{2}{*}{$5-6$} & & \\
\hline & & & & & & No. & $\%$ & & & & & & & \\
\hline Smith & 1899 & + & 一 & $\begin{array}{l}\text { Permanent } \\
\text { and } \\
\text { intermittent }\end{array}$ & 325 & 24 & $7 \cdot 4$ & 40 & 62 & 84 & 44 & 46 & 11 & 14 \\
\hline Worth & 1903 & + & 一. & $\begin{array}{l}\text { Permanent } \\
\text { and } \\
\text { intermittent }\end{array}$ & 1195 & 205 & 17 & 220 & 270 & 218 & 124 & 82 & \multicolumn{2}{|c|}{75} \\
\hline \multirow{2}{*}{ Nordlöw } & \multirow{2}{*}{1942} & \multirow{2}{*}{$\rightarrow$} & \multirow{2}{*}{ Up to 9} & $\begin{array}{l}\text { Permanent } \\
\text { and } \\
\text { intermittent }\end{array}$ & 249 & 75 & 30 & 58 & 37 & 39 & 26 & 8 & 4 & 2 \\
\hline & & & & Intermittent & 50 & 7 & - & 10 & 7 & 11 & 7 & 7 & 1 & 一 \\
\hline \multirow{2}{*}{ Keiner } & 1949 & + & Up to 7 & $\begin{array}{l}\text { Permanent } \\
\text { and } \\
\text { intermittent }\end{array}$ & 332 & 147 & 44 & 91 & 50 & 27 & 13 & 2 & 2 & - \\
\hline & 1951 & + & Up to 7 & $\begin{array}{l}\text { Permanent } \\
\text { and } \\
\text { intermittent }\end{array}$ & 656 & 354 & 55 & 160 & 74 & 42 & 17 & 7 & 2 & - \\
\hline Scobee & 1951 & + & $1-77$ & $\begin{array}{c}\text { Permanent } \\
\text { and } \\
\text { intermittent }\end{array}$ & 456 & 250 & 55 & 80 & 63 & 35 & 10 & 8 & 6 & 4 \\
\hline
\end{tabular}

to estimate fairly accurately the time of onset of squint which is to be expected in a representative group of children under the constant supervision of an ophthalmologist.

The possible sources of systematic error are these:

(1) Failure to notice either the squint or the actual time of its onset.

(2) Reluctance to consult a doctor.

(3) Lapse of memory.

(4) Over-representation of certain age groups.

(1) In the present group of patients, information concerning the child's age at the onset of the squint could not be obtained in 33 out of 518 cases of esotropia (6.4 per cent.). This total of 33 cases is made up of adopted children, patients who had never consulted a doctor previously although the squint was known to be present, and patients in whom the squint had not been observed. As the group is small, and there is no reason to suppose that any particular age is over-represented, it does not influence the age distribution in any particular direction.

Parents sometimes fail to notice the squint until it has been present for some time. This seems less common in cases of wide angles of squint or of intermittent squint. Angles up to $10^{\circ}$ are less common in cases of constant squint (Nordlöw 1942, Tables 19 and 38 ), for which reason a delay in the discovery of these cases should produce only a minor shift towards the older age groups. The age group 0-6 mths constitutes an exception, as there the difficulties are greater. Because infants at this age are disinclined to fixate any definite object, and their eye movements may be uncoordinated, the evaluation is difficult. In the present work, no detailed grading of the age distribution in the first year of life will be attempted.

(2) and (3) The effect on age distribution of the interval between the onset of squint and the first examination is shown in the section headed "Results ". It is obvious that lapses of memory on the part of the parents may influence the result to some extent. 
(4) Previous authors have included only patients who sought medical advice before a certain age, e.g. 7 years. This implies that for those children who began to squint during the first year, at least 6 years remained in which to seek medical advice, while for those who began to squint at the age of 3 to 4 years, only 4 years remained in which to seek advice. This ought to result in over-representation of the first group. In the present work, all cases in the group who began to squint during the first year and who sought advice before the age of 8 years have been included. In the second group (1-2 years) all who sought advice before the age of 9 years were included; in the third group (2-3 years) all who sought advice before the age of 10 years, and in the fourth group (3-4 years) all who sought advice before the age of 11 years. Each of these age groups has thus had 7 years in which to seek medical advice. In the fifth group (4-5 years), however, the interval is 6 years, in the sixth group (5-6 years) it is 5 years, and in the last group (6-7 years) it is 4 years. This implies that odd cases in each of the last three groups might have failed to seek advice. This error is eliminated in the final review of distribution, where only those cases who sought advice within 3 years of the onset of the squint are included.

\section{Material}

A mixed town and coutry population constitutes the basis of the material, which comprises 518 cases, the total number of cases of permanent and intermittent esotropia seen during the 10-year period 1943-1953. In 33 cases information concerning the time of onset of the squint was lacking, and these were therefore excluded, bringing the total

TABLE II

TYPE OF SQUINT AND SEX

DISTRIBUTION IN 485 CASES OF ESOTROPIA

\begin{tabular}{|c|c|c|}
\hline \multirow{2}{*}{ Sex } & \multicolumn{2}{|c|}{ Type of Squint } \\
\hline & Permanent & Intermittent \\
\hline $\begin{array}{l}\text { Male } \\
\text { Female }\end{array}$ & $\begin{array}{l}190 \\
213\end{array}$ & $\begin{array}{l}25 \\
57\end{array}$ \\
\hline Total & 403 & 82 \\
\hline
\end{tabular}
down to 485 . The proportion of permanent and intermittent squints and the sex distribution is set out in Table II.

It was found that intermittent squints constituted $16 \cdot 9 \pm 1 \cdot 7$ per cent. of all cases. This frequency agrees with the results of Lagleyze (1913), who gave $18 \cdot 4$ per cent., and of Nordlöw (1942), who gave $18 \cdot 3 \pm 3 \cdot 2$ and $20 \cdot 1 \pm 3 \cdot 6$ per cent. All the differences are less than once their standard error.

The material shows a preponderance of girls. As regards the permanent squints, where $47 \cdot 2 \pm 2 \cdot 5$ per cent. are boys, the difference is not statistically significant, but of the cases of intermittent squint, only $30.5 \pm 5.1$ per cent. are boys. This may be due to a more frequent occurrence of intermittent squint in girls, which does not seem very probable; it is more reasonable to assume that the parents more frequently seek medical advice for cosmetic reasons when girls are concerned. This implies that the average frequency of intermittent squints is somewhat greater than the value given here $(16 \cdot 9 \pm 1 \cdot 7$ per cent.).

\section{Results}

In investigations previously published (Table I), cases of permanent and intermittent esotropia were tabulated together. By using the same method with the present material the results presented in Table III were obtained.

Thus 51 per cent. were found to develop during the first year of life, 19 per cent. during the second year, 12 per cent. during the third year, 11 per cent. during the fourth year, and 5 per cent. during the fifth year. Table III (overleaf) also shows that a difference exists between the ages of onset of permanent and intermittent esotropia. These are therefore dealt with separately. 
TABLE III

AGE DISTRIBUTION OF ONSET OF SQUINT IN 485 CASES OF PERMANENT AND INTERMITTENT ESOTROPIA EXAMINED WITHIN 7 YEARS OF ONSET

\begin{tabular}{|c|c|c|c|c|c|c|c|c|c|c|c|c|}
\hline \multirow{2}{*}{$\begin{array}{l}\text { Type } \\
\text { of } \\
\text { Squint }\end{array}$} & \multirow{2}{*}{ No. } & \multicolumn{11}{|c|}{ Age at Onset of Squint (yrs) } \\
\hline & & Up to 0.5 & $0 \cdot 5-1$ & $0-1$ & $1-2$ & $2-3$ & $3-4$ & $4-5$ & $5-6$ & $6-7$ & $7-8$ & $8-9$ \\
\hline Permanent & 403 & 177 & 53 & 230 & 77 & 49 & 32 & 9 & 4 & 2 & - & - \\
\hline Intermittent & 82 & 14 & 3 & 17 & 13 & 11 & 19 & 13 & 3 & 3 & 1 & 2 \\
\hline Total & 485 & 191 & 56 & 247 & 90 & 60 & 51 & 22 & 7 & 5 & 1 & 2 \\
\hline $\begin{array}{l}\text { Annual } \\
\text { Percentage }\end{array}$ & - & $39 \cdot 4$ & - & $50 \cdot 9$ & $18 \cdot 6$ & $12 \cdot 4$ & $10 \cdot 5$ & $4 \cdot 5$ & - & 一 & - & - \\
\hline
\end{tabular}

Permanent Squint.-In Table IV, 403 cases of permanent esotropia are tabulated by sex and age at onset. No definite difference between the sexes was found; 43.9 per cent. of squints developed during the first 6 months of life, 57 per cent. during the first year, and 19 per cent. during the second year and thereafter the frequency decreases slowly until the age of 7 years.

TABLE IV

AGE DISTRIBUTION OF ONSET OF SQUINT IN 403 CASES OF PERMANENT ESOTROPIA EXAMINED WITHIN 7 YEARS OF ONSET

\begin{tabular}{|c|c|c|c|c|c|c|c|c|c|c|c|c|}
\hline \multirow{2}{*}{ Sex } & \multirow{2}{*}{ No. of Cases } & \multicolumn{11}{|c|}{ Age at Onset of Squint (yrs) } \\
\hline & & Up to 0.5 & $0 \cdot 5-1$ & $0-1$ & $1-2$ & $2-3$ & $3-4$ & $4-5$ & $5-6$ & $6-7$ & $7-8$ & $8-9$ \\
\hline Male & 190 & 85 & 23 & 108 & 42 & 25 & 9 & 4 & 1 & 1 & - & - \\
\hline Female & 213 & 92 & 30 & 122 & 35 & 24 & 23 & 5 & 3 & 1 & - & - \\
\hline Total & 403 & 177 & 53 & 230 & 77 & 49 & 32 & 9 & 4 & 2 & - & - \\
\hline \multicolumn{2}{|c|}{ Annual Percentage } & $43 \cdot 9$ & - & $57 \cdot 1$ & $19 \cdot 1$ & $12 \cdot 2$ & $7 \cdot 9$ & $2 \cdot 2$ & - & - & - & - \\
\hline
\end{tabular}

Table $\mathrm{V}$ shows the age distribution of these 403 cases according to the TABLE V

403 CASES OF PERMANENT ESOTROPIA DISTRIBUTED ACCORDING TO AGE AT ONSET AND TIME BETWEEN ONSET AND FIRST EXAMINATION

\begin{tabular}{|c|c|c|c|c|c|c|c|c|c|c|c|c|c|c|c|}
\hline \multirow{2}{*}{$\begin{array}{l}\text { Age at Onset of } \\
\text { Squint (yrs) }\end{array}$} & \multirow{2}{*}{$\begin{array}{l}\text { No. of } \\
\text { Cases }\end{array}$} & \multicolumn{14}{|c|}{ Time from Onset of Squint until First Examination (mths) } \\
\hline & & upto6 & $\overline{6-12}$ & $\overline{12-18}$ & $18-24$ & $24-30$ & $\overline{30-36}$ & $\overline{36-42}$ & 24 & $8 \longdiv { 4 8 - 5 4 }$ & $54-60$ & $60-66$ & $66-72$ & $\overline{72-78}$ & $\overline{78-84}$ \\
\hline $0-0.5$ & 177 & 14 & 12 & 24 & 18 & 17 & 13 & 14 & 9 & 9 & 8 & 7 & 6 & 4 & 22 \\
\hline $0.5-1$ & 53 & 12 & 12 & 10 & 3 & $5^{i}$ & 3 & 1 & 1 & 3 & 1 & & & 2 & \\
\hline $1-2$ & 77 & 17 & 14 & 11 & 10 & 3 & 2 & 3 & 3 & 2 & 3 & 3 & 1 & 5 & \\
\hline $2-3$ & 49 & 16 & 10 & 6 & 2 & 3 & 2 & 1 & 3 & 2 & 1 & 1 & & & 2 \\
\hline $3-4$ & 32 & 2 & 6 & 2 & 1 & 5 & 1 & 3 & 2 & 3 & & 3 & & 2 & 2 \\
\hline $4-5$ & 9 & 2 & 5 & 1 & & 1 & & & & 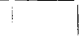 & & & & & \\
\hline $5-6$ & 4 & & 1 & & & 1 & 1 & & & 1 & & & & & \\
\hline $6-7$ & 2 & 2 & & & & & & & & & & & & & \\
\hline Total 0-7 & 403 & 65 & 60 & 54 & 34 & 35 & 22 & 22 & 18 & 20 & 13 & 14 & 7 & 13 & 26 \\
\hline
\end{tabular}


interval between the time of onset and the time of the first examination. The numbers of squints which developed in the first 6 months and in the first 12 months are compared with those developing in the remaining $6 \frac{1}{2}$ and 6 years (Table VI).

\section{TABLE VI}

CHANGE IN AGE DISTRIBUTION OF ONSET OF SQUINT WHEN PERIOD BETWEEN ONSET AND FIRST EXAMINATION VARIES

\begin{tabular}{|c|c|c|c|c|c|c|c|c|}
\hline \multirow{3}{*}{$\begin{array}{l}\text { Time from Onset of } \\
\text { Squint until First } \\
\text { Examination (yrs) }\end{array}$} & \multicolumn{8}{|c|}{ Age at Onset of Squint (yrs) } \\
\hline & \multicolumn{2}{|c|}{ Up to 1} & \multicolumn{2}{|c|}{$1-7$} & \multicolumn{2}{|c|}{ Up to 0.5} & \multicolumn{2}{|c|}{$0 \cdot 5-7$} \\
\hline & No. & $\%$ & No. & $\%$ & No. & $\%$ & No. & $\%$ \\
\hline $\begin{array}{l}1 \\
2 \\
3 \\
4 \\
5 \\
6 \\
7\end{array}$ & $\begin{array}{r}50 \\
105 \\
143 \\
168 \\
189 \\
202 \\
230\end{array}$ & $\begin{array}{r}40 \\
49.3 \\
53 \\
54.2 \\
55.1 \\
55.5 \\
57.1\end{array}$ & $\begin{array}{r}75 \\
108 \\
127 \\
142 \\
154 \\
162 \\
173\end{array}$ & $\begin{array}{r}60 \\
50.7 \\
47 \\
45.8 \\
44.9 \\
44.5 \\
42.9\end{array}$ & $\begin{array}{r}26 \\
68 \\
98 \\
121 \\
138 \\
151 \\
177\end{array}$ & $\begin{array}{r}20.8 \\
31.9 \\
36.3 \\
39 \\
40.2 \\
40.5 \\
43.9\end{array}$ & $\begin{array}{r}99 \\
145 \\
172 \\
189 \\
205 \\
213 \\
226\end{array}$ & $\begin{array}{r}79.2 \\
68.1 \\
63.7 \\
61 \\
59.8 \\
59.5 \\
56.1\end{array}$ \\
\hline
\end{tabular}

It is found that the number of cases of esotropia which developed during the first year increases from 40 to 57 per cent. when the interval between the development of squint and the first examination is increased from 1 to 7 years. The corresponding figures for those squints which developed in the first 6 months of life are 20.8 to 43.9 per cent. The differences between the extreme values, in each case, exceed by three times the standard error and are thus statistically significant. An increase from 40 per cent. after 1 year to 49 per cent. after 2 years can scarcely be attributed to defects of memory. It is perhaps natural that the parents delay longer in seeking advice about a defect which the child has had since birth than about one which develops in a previously healthy child. When a longer period has elapsed, the increase seen in onsets during the first year of life may deperid upon lapses of memory. Somewhere between 2 and 6 years after the development of the squint the correct age distribution should therefore be obtained with the method employed. In the present work, I have chosen 3 years as a suitable period within which the errors due to lapses of memory should be small. After the elapse of 3 years, the late-comers, on the whole, have evened out the deficit.

In Table VII, the age distribution at the onset of squint is given for those patients who came for examination within 3 years of onset. It shows that 36.3 per cent. of the cases of permanent esotropia developed during the first 6 months of life,

TABLE VII

AGE DISTRIBUTION OF ONSET OF SQUINT IN 270 CASES OF PERMANENT ESOTROPIA EXAMINED WITHIN 3 YEARS OF ONSET OF SQUINT

\begin{tabular}{|c|c|c|c|c|c|c|c|c|c|}
\hline \multirow{2}{*}{ No. of Cases } & \multicolumn{9}{|c|}{ Age at Onset of Squint (yrs) } \\
\hline & $0-0.5$ & $0 \cdot 5-1$ & $0-1$ & $1-2$ & $2-3$ & $3-4$ & $4-5$ & $5-6$ & $6-7$ \\
\hline 270 & 98 & 45 & 143 & 57 & 39 & 17 & 9 & 3 & 2 \\
\hline Percentage & 36.3 & - & 53 & 21.1 & 14.4 & 6.3 & 3.3 & - & - \\
\hline
\end{tabular}


$53 \pm 3$ per cent. during the first year, $21 \cdot 1 \pm 2 \cdot 5$ per cent. during the second years $14 \cdot 4 \pm 2 \cdot 1$ per cent. during the third year, $6 \cdot 3 \pm 1 \cdot 5$ per cent. during the fourth yea and $3 \cdot 3 \pm 1 \cdot 1$ per cent. during the fifth year. The figures so obtained should thu correspond closely to the true age distribution of the onset of permanent esotropia.

Intermittent Squint.*-On investigating all cases (a total of 82) which were exam ined for the first time within 7 years of the development of squint, it is found that approximately equal numbers develop during each of the first 5 years of life (Table VIII). This tendency is even more marked in the 63 cases which were examined within 3 years of the development of squint. The remaining 17 per cent $\overbrace{\Omega}^{\Phi}$ developed between the ages of 5 and 9 years. Here also a certain delay is observects for the first age group (up to 1 year), but it seems to be evened out 2 years after the onset of the squint. Otherwise, no significance can be deduced from the intervat which elapsed between the onset of squint and the first examination.

TABLE VIII AGE DISTRIBUTION OF ONSET OF SQUINT IN 82 CASES OF INTERMITTENT:

Time from On- No. set of Squint Age at Onset of Squint (yrs) until First Exam- Cases $\overline{0-0 \cdot 5} \overline{0 \cdot 5-1} \overline{0-1} \overline{1-2} \overline{2-3} \overline{3-4} \overline{4-5} \overline{5-6} \overline{6-7} \overline{7-8} \overline{8-9}$ 응 ination $(\mathrm{yrs})$

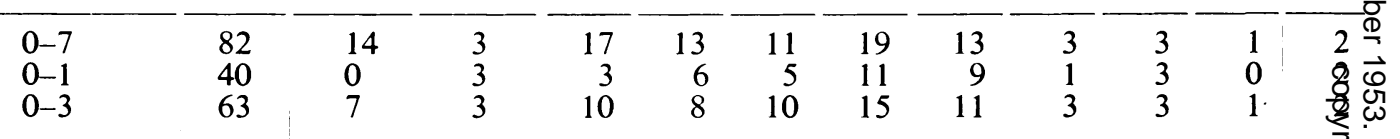

The number of cases of intermittent esotropia is small, but it may be increaseds by the addition of another fifty cases which were collected in approximately thea same way (Nordlöw, 1942, Table 30). The age distribution at the onset of squint in the two groups combined is set out in Table IX, which shows that 84 per $\Rightarrow$ cent. developed during the first 5 years of life with approximately equal numbers 3 in each year. A preponderance, although not statistically significant, is found for the group 3 to 4 years. It is possible that this preponderance might be found significant in a larger number of cases.

TABLE IX

AGE DISTRIBUTION OF ONSET OF SQUINT IN 132 CASES OF INTERMITTENT ESOTROPIA EXAMINED APPROXIMATELY WITHIN 7 YEARS OF ONSET OF SQUINT

\begin{tabular}{|c|c|c|c|c|c|c|c|c|c|}
\hline \multirow{2}{*}{ No. of Cases } & \multicolumn{8}{|c|}{ Age at Onset of Squint (yrs) } & \multirow[b]{2}{*}{$8-9$} \\
\hline & $0-1$ & $1-2$ & $2-3$ & $3-4$ & $4-5$ & $5-6$ & $6-7$ & $7-8$ & \\
\hline 132 & 20 & 23 & 18 & 30 & 20 & 10 & 4 & 1 & 2 \\
\hline
\end{tabular}

This difference in the age distribution at the onset of permanent and intermittent esotropia causes the intermittent squint to form an increasingly large proportion of the annual groups, the later it commences (Table $X$, $\frac{0}{0}$ opposite). 
TABLE X

ANNUAL FREQUENCY OF INTERMITTENT SQUINTS IN 333 PERMANENT AND INTERMITTENT SQUINTS EXAMINED WITHIN 3 YEARS OF ONSET OF SQUINT

\begin{tabular}{|c|c|c|c|c|c|c|c|c|c|c|}
\hline \multirow{2}{*}{ Type of Squint } & \multirow{2}{*}{$\begin{array}{l}\text { Time from Onset } \\
\text { of Squint until First } \\
\text { Examination (yrs) }\end{array}$} & \multicolumn{9}{|c|}{ Age at Onset of Squint (yrs) } \\
\hline & & $0-1$ & $1-2$ & $2-3$ & $3-4$ & $4-5$ & $5-6$ & $6-7$ & $7-8$ & $8-9$ \\
\hline $\begin{array}{l}\text { Permanent } 270 \\
\text { Intermittent } 63\end{array}$ & $0-3$ & 153 & 65 & 49 & 32 & 20 & 6 & 5 & 1 & 2 \\
\hline Intermittent 63 & $0-3$ & 10 & 8 & 10 & 15 & 11 & 3 & 3 & 1 & 2 \\
\hline $\begin{array}{l}\text { Percentage } \\
\text { Intermittent }\end{array}$ & $0-3$ & 6.5 & 12.3 & 20.4 & 46.9 & 55 & - & - & - & - \\
\hline
\end{tabular}

Of those squints which develop during the first year of life, the intermittent squints constitute 6.5 per cent. Their relative frequency increases each year, and at 4 to 5 years reaches 55 per cent. In stating the percentage of intermittent squints in a given group of children, it must be decided whether an average for the entire period during which the squints developed, or a definite age group, is required.

\section{Discussion}

Previous investigations by Nordlöw, Keiner, and Scobee, together with the present work, show that esotropia develops more frequently during the first year of life than at any other time. Thus the previous idea that the majority of cases of esotropia develop between the age of 2 and 4 years cannot be correct.

In determining the age distribution, consideration must be given to possible sources of error in the method employed. If the possibility of over-representation of early age groups is eliminated, this investigation shows that $50 \cdot 9 \pm 2 \cdot 27$ per cent. of cases of permanent and intermittent esotropia develop during the first year of life(Keiner gave 54.9 per cent., and Scobee 55 per cent.) The difference was anticipated, as these authors neglected the sources of error mentioned and Scobee also included a number of older squints. The difference is less than twice its standard error, and the agreement must therefore be considered valid for the three investigations.

Nordlöw (1942) found that 30 per cent. of cases of esotropia develop during the first year of life; this is 20.9 per cent. less than the figure arrived at in the present investigation, but it must be remembered that the previous investigation was the first in which the preponderance of cases occurring during the first year of life was demonstrated. Once this fact had become known, more particular attention could be paid to the information supplied by the parents. This has meant the discovery of an even greater preponderance of cases of permanent esotropia which developed during the first year of life.

In the present investigation, consideration was also given to errors due to 
the interval which elapsed between the onset of squint and the first examination. Further, the difference in age distribution between permanent and intermittent squint was taken into account.

It has been demonstrated that the age distribution of onset in cases of intermittent esotropia differs from that in cases of permanent esotropia. Other differences between the two types of squint (mechanism of development and spontaneous changes during the years of growth) have previously been demonstrated by Nordlöw $(1942,1951)$.

\section{Summary}

A total of 403 cases of permanent squint and 82 cases of intermittent squint, all of which were examined within 7 years of the development of the squint, has been collected by the author during a 10 -year period.

The significance of some of the sources of error of the method of study is discussed, and their effect as far as posssible eliminated. It has been found that, of the cases of permanent esotropia examined, $36 \cdot 3$ per cent. developed during the first 6 months of life, $53 \pm 3$ per cent. during the first year, $21 \cdot 1 \pm$ $2 \cdot 5$ per cent. during the second year, $14 \cdot 4 \pm 2 \cdot 1$ per cent. during the third year, $6 \cdot 3 \pm 1 \cdot 5$ per cent. during the fourth year, $3 \cdot 3 \pm 1 \cdot 1$ per cent. during the fifth year, and the remainder during the sixth and seventh years of life.

The age distribution of the onset of intermittent squint is different; 84 per cent. developed during the first 5 years of life, the numbers in each year being approximately equal, with a tendency to preponderance at 3 to 4 years.

The intermittent squints occuring in each of the first 5 years of life comprised 6.5 per cent., $12 \cdot 3$ per cent., 20.4 per cent., $46 \cdot 8$ per cent., and 55 per cent. of the whole (i.e. the older the child at the onset of squint the more frequent the occurrence of intermittent squint).

\section{REFERENCES}

Keiner, G. B. J. (1949). Ned. T. Geneesk., 93, 1650.

- (1951). "New Viewpoints on the Origin of Squint". Nijhoff, The Hague.

Lagleyze, P. (1913). "Du Strabisme; recherches €tiologiques, pathogénie, mécanisme du traitement". Rousse', Paris.

Nordlöw, W. (1942). Acta. ophthal. Kbh., Suppl. 20.

(1951). Ibid., 29, 383.

SCOBEE, R. G. (1951). Amer. J. Ophthal., 34, 817.

Smith, Priestley (1899). XI Int. Cong. Ophthal., Utrecht.

WORTH, C. (1903). "Squint : Its Causes, Pathology and Treatment". Bale and Danielsson, London. 